\title{
НАУЧНО-ТЕХНИЧЕСКИЙ ПЕРЕВОД В ОБЛАСТИ ТЕОРИИ И ПРАКТИКИ ЗУБЧАТЫХ ЗАЦЕПЛЕНИЙ КАК ВИД ПРОФЕССИОНАЛЬНОЙ ДЕЯТЕЛЬНОСТИ
}

\section{SCIENTIFIC AND TECHNICAL TRANSLATION IN THEORY AND PRACTICE OF GEARING AS PROFESSIONAL ACTIVITY \\ N. Barmina}

Summary: The paper summarizes the practical experience of scientific and technical translation in the theory and practice of gearing at the scientific department of the technical university for the period of 19952020. Different kinds of translation activity are described; the main difficulties are discussed that arise within translating and interpreting. Special attention is paid to the main components of the translator's professional activity. Conclusions are made on the necessity to improve continuously the cognitive skills both in the subject area and the foreign language, along with the technical skills of translation.

Keywords: scientific and technical translation, components of translational activity, cognitive component, practical component, translating, interpreting.

\section{Введение}

$\Pi$ рофессиональная деятельность в области научнотехнического перевода включает в себя когнитивно-содержательный, коммуникационный, практический и многие другие компоненты, необходимые для успешного выполнения поставленной переводчику задачи [1, 2]. В частности, когнитивно-содержательный ком ппонент подразумевает знания основных положений теории переволда, вариантов переводческой стратегии и технических приемов перевода, а также предполагает сформированность лексических, грамматических, стиллистических и переводческих знаний [3]. Кроме того, переводческая деятельность в техническом вузе предполагает наличие у переводчика соответствующих компетенций в определенной области науки и техники. Эти знания необходимы для понимания текста ори-гинала и создания текста перевода с учетом специфики профессиональной области.

Как отмечалось в [4], в последней трети XX века достижения советской науки в области машиностроения пользовались уважением в мире, и ведущие научнотехнические журналы, такие как «Вестник машиностроения», «Станки и инструмент», «Машиноведение», полностью или частично переиздавались на английском
Бармина Наталья Александровна К.т.н., дочент, ФГБОУ ВО «ИжГТУ имени М.Т. Калашникова» barmina-nat@mail.ru

Аннотация: В статье обобщен практический опыт научно-технического перевода в области зубчатых передач в рамках деятельности научного подразделения высшего учебного заведения за период с 1995 по 2020 годы. Описаны различные виды деятельности и перечислены основные трудности, с которыми сталкивается переводчик в процессе письменного и устного перевода. Особое внимание уделено основным компонентам профессиональной деятельности переводчика. Сделаны выводы о необходимости постоянного совершенствования когнитивных умений как в предметной области, так и в области иностранного языка, а также технических навыков работы переводчика.

Ключевые слова: научно-технический перевод, компоненты переводческой деятельности, когнитивный компонент, практический компонент, письменный перевод, устный перевод.

языке. К сожалению, существовавший в те годы «железный занавес» между Советским Союзом и западным миром существенно мешал общению российских авторов с их зарубежными издателями. Переводы статей выполнялись не специалистами в области теории механизмов и машин, они содержали терминологические ошибки и не были авторизованы. Первыми фундаментальными англоязычными работами в области теории зубчатых зацеплений были две статьи профессора Ф.Л. Литвина и его соавторов [5, 6], в которых зарубежному читателю были представлены важнейшие на тот момент достижения российской школы теории зацеплений. В 90-е годы с крушением «железного занавеса» российские исследователи начали активно участвовать в международных конференциях. В связи с выходом российских ученых на международную арену остро встал вопрос об обеспечении адекватного, профессионально грамотного перевода русских технических текстов на английский язык язык международного общения ученых разных стран.

Целью данной работы является анализ основных видов переводческой деятельности в рамках технического вуза за период с 1995 по 2020 годы и выявление основных трудностей, с которыми сталкивается переводчик в рамках работы в области машиностроения, в частности, в области теории и практики зубчатых зацеплений. 
Научное подразделение «Институт механики имени профессора ГольАфарба В.И.» - история, научные направления, основные направления Аеятельности

ФГБОУ ВО «Ижевский государственный технический университет (ИжГТУ) имени М.Т. Калашникова» является одним из ведущих технических вузов в Приволжском федеральном округе, обеспечивающим подготовку высококвалифицированных инженерных кадров. На протяжении уже нескольких десятилетий университет активно развивает международное сотрудничество в научной и образовательной сферах. Одной из ведущих в международном научно-техническом сообществе в области зубчатых передач и редукторостроения научных школ является «Институт механики», научное подразделение университета, основанное 1 февраля 1994 года под руководством доктора технических наук, активного международного деятеля в области зубчатых передач, профессора Вениамина Иосифовича Гольдфарба (19412019).

Основными направлениями научной и инновационной деятельности «Института механики» являются проектирование передач и редукторов червячного типа, синтез новых разновидностей передач, разработка конструкций и технологии их изготовления, теоретические и экспериментальные исследования передач и редукторов, а также производство, испытания и внедрение прогрессивных наукоемких передач и редукторов. Наряду с научной и производственной работой сотрудники «Института механики» активно занимаются организацией и проведением общероссийских и международных конференций по зубчатым передачам с публикацией их результатов на русском и английском языках и другой издательской деятельностью. Эта работа потребовала наличия научных кадров с базовым техническим образованием (когнитивный компонент) в области машиностроения, которые при этом владели бы английским языком в этой профессиональной области (практический компонент). Начиная с 1994 года, ИжГТУ имени М.Т. Калашникова ведет подготовку специалистов по программе «Переводчик в сфере профессиональной коммуникации» с правом на осуществление профессиональной деятельности в области перевода. В 1995 году автора данной статьи пригласили к сотрудничеству в «Институт механики», и по настоящее время письменный и устный научно-технический перевод литературы в области зубчатых передач является основным видом профессиональной деятельности.

\section{Аспекты научно-технического перевода в рамках профессиональной Аеятельности в научном подразделении вуза}

Как уже говорилось выше, «Институт механики» с мо- мента его основания активно занимается различными видами международной научной деятельности, которые требуют от переводчика постоянно совершенствовать когнитивные компетенции, как в области зубчатых передач, так и в области профессионального перевода. Поэтому на первый план выходит когнитивно-содержательный компонент профессиональной деятельности переводчика, который включает в себя умение постоянно обогащать свои знания, искать новую информацию, продуктивно использовать различные источники информации в самых разных направлениях, связанных с теорией и практикой исследования и производства зубчатых передач. Еще одним из важнейших компонентов языковых знаний является знание терминологии, то есть узнавание терминов на иностранном языке и употребление эквивалентов к ним для передачи терминов на языке перевода [1-3].

Далее подробно описываются основные виды научно-технического перевода, которые осуществлялись автором в рамках профессиональной деятельности в разные периоды времени.

\section{Письменный перевод научных статей в научно-технический журнал «Передачи и трансмиссии»}

В настоящее время журнал «Передачи и трансмиссии» стал уже историей, но он был первым и единственным в своем роде двуязычным журналом, где публиковались результаты научных исследований в области зубчатых передач и трансмиссий, выполненные иностранными учеными и учеными из России. Все статьи публиковались параллельно на русском, и на английском языке, что само по себе было пионерским решением и послужило мощным толчком к международному общению и сотрудничеству ученых, занимающихся зубчатыми передачами по всему миру. Журнал издавался с 1991 по 2004 годы до трех раз в год силами «Института механики» при поддержке Ассоциации инженеров механических трансмиссий (Россия), Технического университета Брно (Словакия) и Словацкого технического университета в Братиславе, Технического университета в Ноттингеме (Великобритания). Он рассылался в десятки российских и зарубежных вузов и на предприятия, и уже в 1994 году он стал официальным журналом Международной Федерации по Теории Механизмов и Машин - International Federation for the Promotion of Mechanism and Machine Science (IFToMM, http://iftomm.net/).

Основные трудности переводчиков в 1990x годах были связаны с практически полным отсутствием на тот момент международного сотрудничества между отечественными и иностранными учеными в этой области, рассогласованностью и неоднозначностью научно-технических терминов и вкладываемых в них по- 
нятий учеными-«зубчатниками» в России и за рубежом, отсутствием специальных словарей в области зубчатых передач в бумажном и тем более электронном виде, а также отсутствием какого-либо накопленного опыта перевода в этой области. Тем не менее, задачи обеспечения адекватного перевода, понятного как российским ученым (при переводе работ англоязычных авторов на русский язык), так и их зарубежным коллегам (при переводе работ русскоязычных авторов на английский язык) успешно решались при активном консультировании с российскими и иностранными специалистами. К слову, именно общение и консультирование со специалистами в области зубчатых передач (особая благодарность с.н.с., канд. техн. наук Сергею Абрамовичу Лагутину за многолетнее содействие и всестороннюю помощь в работе с англоязычной лексикой и терминологией в области зубчатых передач) и изучение специализированной научно-технической литературы на русском и английском языках стали самыми эффективными составляющими когнитивного познания.

\section{Письменный перево $\Delta$ научных, учебных и учебно-методических изАәний ученых ИжГТУ}

На рубеже XX и XXI веков международная научная деятельность и публикационная активность в ИжГТУ имени М.Т. Калашникова развивались не только в рамках НП «Институт механики». Многие научные школы начали публиковать статьи и книги на английском языке. Но в связи с отсутствием опыта перевода технической литературы статьи российских ученых нередко возвращались из зарубежных издательств с отказом в публикации и формулировкой «слабый английский», а также с предложением отредактировать перевод за определенную плату. При этом заметим, что если авторы соглашались на редактирование перевода, то полученный перевод, как правило, удовлетворял требованиям английской грамматики, но содержал ошибки в терминологии, затруднявшие понимание существа работы. Таким образом, основной задачей переводчика в то время было накопление необходимого опыта работы с иностранными издательствами, изучение их требований к качеству предоставляемых научных работ и требований к их оформлению по международным стандартам. Грамотные переводы на английский язык научно-технических статей и монографий магистрантов, аспирантов, преподавателей и научных сотрудников ИжГТУ и других российских вузов сделали возможным не только публикации в международных изданиях, но и участие российских ученых в международных конференциях.

Кроме того, российские вузы, в том числе и ИжГту, начали развитие международных образовательных программ, что привлекло иностранных студентов в российские вузы и привело к необходимости издавать специализированные учебники на английском языке. Ниже перечислены некоторые учебники, переведенные автором в рамках профессиональной переводческой деятельности.

1. Airapetov E.L. State of the Art and Prospects of Gear Strength and Loading Analysis Methods, 2000 (опубликовано в Словакии).

2. Abramov I.V., Ibragimov A.U., Golubkov N.S. Gears and Their Calculation, 2001 (опубликовано в Венгрии).

3. Korotkin V.I., Onishkov N.P., Kharitonov Yu.D. Novikov Gears. Achievements and Developments (Mechanical Engineering Theory and Applications), 388 p., 2010, ISBN-13: 978-1617611933 (опубликовано в США)

4. Yakimovich B.A., Tenenev V.A. Genetic Algorithms in System Simulation, 2012 (опубликовано в Словакии).

5. Dobrovolsky V.I., Dobrovolsky S.V. Mechanics of Materials. Text book - Ижевск: Изд-во ИжГТу, 2012, $-408 \mathrm{p}$.

6. Dobrovolsky V.I., Dobrovolsky S.V. Strength, Rigidity and Stability Analyses of Construction Elements. Study Guide - Ижевск: Изд-во ИжГТУ, 2012, - 322 p.

7. Dobrovolsky V.I., Dobrovolsky S.V. Mechanical Tests of Materials. Study Guide - Ижевск: Изд-во Ижгту, 2012, - 266 p.

8. Russian State Standard 22850-77. Spiroid gears. Terms, definitions and designations.

Учебники и учебно-методические пособия $(1,5,6,7)$ переведены совместно со старшим преподавателем кафедры «Английский язык» ИжГТУ Волковой Д.А.

С 2014 года в рамках своей профессиональной деятельности автор наладил сотрудничество с Издательством ИжГТУ имени М.Т. Калашникова по научно-техническому переводу аннотаций статей и других информационных материалов с русского языка на английский для журналов «Вестник ИжГТУ» и «Интеллектуальные системы в производстве» и на сайте этих журналов (входят в перечень изданий, рекомендованных ВАК). Основными трудностями для переводчика в этой работе являются сжатые сроки подготовки материалов и многообразие тематик (педагогика, экономика, системный анализ и управление, машиностроение, приборостроение и др.).

\section{$\Delta$ еятельность ученых ИжГТУ в МежАународной Федерации по Теории Механизмов и Машин (IFTOMM)}

Международная Федерация по Теории Механизмов и машин была основана в 1969 году по инициативе советского ученого, академика И.И. Артоболевского. Она объединяет 45 стран и включает в себя четыре Постоянные Комиссии и 14 Технических Комитетов http://iftomm.net/. Начиная с 1994 года, ученые ИжГТУ принимают активное участие в деятельности этой организации. В частности, 
профессор В.И. Гольдфарб в период с 1994 по 2019 годы занимал в этой Федерации должности члена Технического Комитета по Зубчатым Передачам, председателя этого комитета, председателя Постоянной Комиссии по Коммуникациям, Публикациям и Архивингу, Вице-Президента Федерации. С 2014 года членом Постоянной Комиссии по Образованию является проф. Э.Г. Крылов. С 2013 года по настоящее время членом Постоянной Комиссии по Публикациям, Коммуникациям и Архивингу является С.н.с. Н.А. Бармина.

В обязанности представителя от «Института механики» в этой комиссии входят подготовка и публикация ежегодного Информационного отчета-бюллетеня (Newsletter) о деятельности IFTоММ. Входят также: координирование графика проведения всемирных конгрессов, конференций и совещаний, информирование членов IFToMМ о предстоящих мероприятиях, создание официальной страницы IFToMM на сайте wikipedia.org на русском и английском языках, сотрудничество с Техническими Комитетами, а также архивирование документации о деятельности IFToMМ. Помимо перечисленных основных разнообразных обязанностей, в круг задач автора этой работы в период с 2011 по 2015 год входило регулярное сопровождение, обновление и модернизация официального сайта IFToMM на английском языке. При этом необходимо было вести активную переписку и Skype-переговоры с другими членами этой Федерации (на данный момент их порядка 500) как с носителями английского языка, так и с теми учеными, для которых этот язык был языком международного общения. С учетом трудностей социокультурного и психологического характера, разницы временных поясов и т.д. на первый план вышли технические компоненты профессиональной деятельности переводчика. Это, в первую очередь, знание различных интернет программ начала 2010x годов (Skype, videoconferences и пр.), необходимость интернет-поиска англоязычной научно-технической литературы и стандартов в области зубчатых передач, а также навыки опытного пользователя ПК с элементами программирования в области администрирования международного сайта.

\section{Устный последовательный перево в рамках организашии и провеАения НП «Институт механики» меххународных научных мероприятий в области зубчатых передач}

С начала 21 века научное подразделение «Института механик» осталось практически единственным коллективом, который продолжил практику организации и проведения общероссийских и международных семинаров, конференций и симпозиумов по зубчатым передачам под общим названием «Теория и практика зубчатых передач и редукторостроения». В рамках подготовки международного мероприятия переводчик должен осуществлять такие различные виды переводческой деятельности, как: переписка на английском языке, подготовка большого количества официальных документов на английском и русском языках, телефонные переговоры, подготовка двуязычного сборника трудов, перевод презентаций, а также обеспечение последовательного перевода с/на английский язык непосредственно во время проведения мероприятия. Основной трудностью при этом является необходимость выполнять эти виды одновременно и в сжатые сроки. Первым проведенным в Ижевске международным мероприятием был Международный симпозиум «Развитие геометрической теории зубчатых зацеплений» (1993 г.), далее конференции проводились регулярно (Международный симпозиум «Прогрессивные зубчатые передачи» в 1994 г., Международная конференция «Теория и практика зубчатых передач» в 1996, 1998, 2004, 2008 гг., Международный научный семинар “Современные информационные технологии. Проблемы проектирования, исследования и производства зубчатых передач" в 2001 г.). Это позволило накопить необходимый опыт устной переводческой деятельности в области зубчатых передач. В 2014 году состоялся Международный Симпозиум «Теория и практика зубчатых передач» - крупнейший международный научный форум по зубчатым передачам в России, который собрал 100 участников из 12 стран. Во время работы Симпозиума устный перевод обеспечивали шесть специалистов, имеющих как техническое образование в области машиностроения, так и диплом переводчика в сфере профессиональной коммуникации, то есть обладающих когнитивными умениями и практическими навыками в необходимой области знаний.

\section{ИзАание англоязычных сборников научных статей по зубчатым передачам в серии ТММ в межАународном издательстве Springer}

По результатам успешного проведения в 2014 году Международного Симпозиума «Теория и практика зубчатых передач» сотрудникам «Института механики» поступило предложение от международного издательства Springer начать издание серии тематических сборников научных статей по вопросам исследования, проектирования, производства и испытаний зубчатых передач. Этот проект стал первым и во многом уникальным не только для научного подразделения и для вуза, но и для всего международного зубчатого сообщества. Авторы книг - ведущие ученые и начинающие исследователи из России и других стран, занимающиеся научными исследованиями и внедрением в реально производство зубчатых передач. Представленные в сборниках исследования охватывают традиционные цилиндрические, конические, червячные, спироидные, планетарные передачи, а также новые виды передач, в том числе передачи с пластмассовыми колесами. К настоящему времени уже опубликованы три сборника (2016 [7], 2018 [8], 
2020 [9]), каждый из которых включает более 20 статей ведущих ученых в области зубчатых передач из России, Беларуси, Японии, Германии, Болгарии, США, Канады, Словении, Польши, Сербии, Италии, Испании и Китая.

Работа над всеми сборниками идет по одинаковому алгоритму, занимающему с момента подачи заявки до выхода книги в свет примерно год-полтора: переписка с издательством, оформление и подача заявки, работа с авторами, перевод статьей, работа с техническим редактором от издательства и печать бумажной версии. Работа редакторов (проф. В.И. Гольдфарб, проф. Е.С. Трубачев, с. Н. С. Н.А. Бармина) заключалась в тщательном отборе авторов и рецензировании статей, переводе части статей с русского на английский, редактирование переводов, сделанных некоторыми русскоязычными авторами самостоятельно, а также сотрудничество с издательством. Традиционно редакторы сборников отказываются от услуг переводчиков издательства Springer, взяв на себя обязательство предоставить грамотные переводы статей русскоязычных авторов. Область зубчатых передач имеет свою специфику и сложности в плане терминологии: многие понятия описываются разными учеными из разных стран по-разному, нет утвержденных единых стандартов для перевода терминов. Поэтому здесь переводчик в рамках своей профессиональной деятельности сталкивается с очень разнообразными задачами: переписка с ведущими специалистами из разных стран, обсуждение тех или иных терминов, «штудирование» англоязычных монографий и статей классиков в области зубчатых передач. Он должен иметь и применять многолетний накопленный опыт перевода и публикаций статей на английском языке в известных издательствах и сборниках трудов международных конференций. Носитель языка (сотрудник издательства Springer), имеющий техническое образование, но не являющийся ученым в области зубчатых передач, лишь «причесывает» перевод и вносит стилистические правки для лучшей «читаемости» текста широким кругом читателей. В настоящее время одобрена заявка и начата работа по подготовке четвертого сборника в этой серии книг.

\section{Зак^ючение}

Научно-технический перевод в области зубчатых передач как вид многолетней профессиональной деятельности является очень разносторонним творческим процессом, который нельзя ограничить или классифицировать как письменный или устный перевод. Переводчик постоянно сталкивается с разнообразными вызовами современной реальности. На этапе становления переводчика это было полное отсутствие когнитивной компетенции, доступной литературы и налаженных связей со специалистами в этой области в России и за рубежом. Затем потребовалось освоение разнообразных технических средств перевода и коммуникаций (интернет, Skype, электронные словари, всевозможные компьютерные программы и приложения) с постоянным совершенствованием когнитивных умений в сфере зубчатых передач и английского языка. В связи с постоянным развитием науки и техники, а также совершенствованием методов и средств перевода, процесс когнитивного познания является непрерывным как в предметной области (зубчатые передачи как раздел теории механизмов и машин), так и в области научно-технического перевода.

\section{ЛИТЕРАТУРА}

1. Вербицкая М.В., Соловов М.Ю. Теория и практика перевода компоненты и уровни переводческой компетенции. Вестн. Моск. ун-та. Сер. 19. Лингвистика и межкультурная коммуникация. 2010. № 4.

2. Телешова Е.А. Когнитивный компонент профессиональной компетентности переводчика. Южно-Уральский государственный университет, г. Челябинск Вестник ЮУрГУ. Серия «Лингвистика». 53 2016. Т. 13, № 3. С. 52-57.

3. Чиркова Е.В., Беккер И.Л. Структура и специфика профессиональной переводческой деятельности спелциалистов по связям с общественностью // Известия ПГПУ им. В.Г. Белинского. 2011. № 24. С. 856-861.

4. Бабичев Д.Т., Лагутин С.А., Бармина Н.А Обзор работ русской школы теории и геометрии зацеплений. Часть 2: Развитие классической теории зацеплений и становление теории реальных зацеплений в 1976-2000 годы. // Теория механизмов и машин. С-Петербург, Том 15, №3(35), 2017, С. 86-130.

5. Litvin F.L., Petrov K.M., and Ganshin V.A., The Effect of Geometrical Parameters of Hypoid and Spiroid Gears on its Quality Characteristics, // ASME Journal of Engineering for Industry, Vol. 96, 1974, pp. 330-334.

6. Litvin F.L., Krylov N.N., and Erikhov M.L., Generation of Tooth Surfaces by Two-Parameter Enveloping, Mechanism and Machine Theory, Vol. 10, No. 5, 1975, pp. 365-373.

7. V. Goldfarb N. Barmina. Theory and Practice of Gearing and Transmissions: In Honor of Professor Faydor L. Litvin (2016) https://www.springer.com/gp/ book/9783319197395

8. V. Goldfarb, E. Trubachev, N. Barmina. Advanced Gear Engineering (2018) https://www.springer.com/gp/book/9783319603988

9. V. Goldfarb, E. Trubachev, N. Barmina. New approaches to gear design and production (2020) https://link.springer.com/book/10.1007/978-3-030-34945-5

(c) Бармина Наталья Александровна (barmina-nat@mail.ru).

Журнал «Современная наука: актуальные проблемы теории и практики» 